\title{
Effects of ketamine administration on mTOR and reticulum stress signaling pathways in the brain after the infusion of rapamycin into prefrontal cortex
}

\author{
Helena M. Abelaira a , Gislaine Z. Réus ${ }^{\text {a, * }}$, Zuleide M. Ignácio a, \\ Maria Augusta B. dos Santos a, Airam B. de Moura a, Danyela Matos a , Júlia P. Demo a, \\ Júlia B.I. da Silva ${ }^{\text {a }}$, Monique Michels ${ }^{\mathrm{b}}$, Mariane Abatti ${ }^{\mathrm{b}}$, Beatriz Sonai ${ }^{\mathrm{b}}$, \\ Felipe Dal Pizzol b', André F. Carvalho ${ }^{\mathrm{c}}$, João Quevedo ${ }^{\mathrm{a}, \mathrm{d}, \mathrm{e}, \mathrm{f}}$ \\ a Laboratório de Neurociências, Programa de Pós-Graduação em Ciências da Saúde, Unidade Acadêmica de Ciências da Saúde, Universidade do Extremo Sul \\ Catarinense, Criciúma, Brazil \\ ${ }^{\mathrm{b}}$ Laboratório de Fisiopatologia Experimental, Programa de Pós-Graduação em Ciências da Saúde, Unidade Acadêmica de Ciências da Saúde, Universidade \\ do Extremo Sul Catarinense, Criciúma, Brazil \\ ${ }^{\mathrm{c}}$ Translational Psychiatry Research Group and Department of Clinical Medicine, Faculty of Medicine, Federal University of Ceara, Fortaleza, CE, Brazil \\ ${ }^{\mathrm{d}}$ Translational Psychiatry Program, Department of Psychiatry and Behavioral Sciences, McGovern Medical School, The University of Texas Health Science \\ Center at Houston (UTHealth), Houston, TX, USA \\ e Center of Excellence on Mood Disorders, Department of Psychiatry and Behavioral Sciences, McGovern Medical School, The University of Texas Health \\ Science Center at Houston (UTHealth), Houston, TX, USA \\ ${ }^{\mathrm{f}}$ Neuroscience Graduate Program, The University of Texas Graduate School of Biomedical Sciences at Houston, Houston, TX, USA
}

\section{A R T I C L E I N F O}

Article history:

Received 6 July 2016

Received in revised form

13 October 2016

Accepted 1 December 2016

\section{Keywords:}

mTOR

ER stress

Glutamatergic system

Ketamine

Animal model

Major depressive disorder

\begin{abstract}
A B S T R A C T
Recent studies show that activation of the mTOR signaling pathway is required for the rapid antidepressant actions of glutamate N-methyl-D-aspartate (NMDA) receptor antagonists. A relationship between mTOR kinase and the endoplasmic reticulum (ER) stress pathway, also known as the unfolded protein response (UPR) has been shown. We evaluate the effects of ketamine administration on the mTOR signaling pathway and proteins of UPR in the prefrontal cortex (PFC), hippocampus, amygdala and nucleus accumbens, after the inhibiton of mTOR signaling in the PFC. Male adult Wistar rats received pharmacological mTOR inhibitor, rapamycin $(0.2 \mathrm{nmol})$, or vehicle into the PFC and then a single dose of ketamine $(15 \mathrm{mg} / \mathrm{kg}$, i.p.). The immunocontent of mTOR, eukaryotic initiation factor $4 \mathrm{E}$-binding protein 1 (4E-BP1), eukaryotic elongation factor 2 kinase (eEF2K) homologous protein (CHOP), PKR-like ER kinase (PERK) and inositol-requiring enzyme 1 (IRE1) - alpha were determined in the brain. The mTOR levels were reduced in the rapamycin group treated with saline and ketamine in the PFC; p4EBP1 levels were reduced in the rapamycin group treated with ketamine in the PFC and nucleus accumbens; the levels of peEF2K were increased in the PFC in the vehicle group treated with ketamine and reduced in the rapamycin group treated with ketamine. The PERK and IRE1-alpha levels were decreased in the PFC in the rapamycin group treated with ketamine. Our results suggest that mTOR signaling inhibition by rapamycin could be involved, at least in part, with the mechanism of action of ketamine; and the ketamine antidepressant on ER stress pathway could be also mediated by mTOR signaling pathway in certain brain structures.
\end{abstract}

(c) 2016 Elsevier Ltd. All rights reserved.

\footnotetext{
* Corresponding author. Laboratory of Neurosciences, University of Southern Santa Catarina, Criciuma, SC, 88806-000, Brazil.

E-mail address: gislainezilli@hotmail.com (G.Z. Réus).
}

\section{Introduction}

Major depressive disorder (MDD), a serious mental disorder, is the leading cause of disability and a major contributor to disease burden in the world's population (Ghasemi et al., 2014). Despite antidepressant treatment patients continue to experience low 
remission rates, residual subsyndromal symptoms, relapses and persistent functional impairment (Naughton et al., 2014). Unfortunately, the delayed onset time and the low remission rate of conventional antidepressants are still major challenges (Giacobbe et al. 2009; Machado-Vieira et al., 2009). Therefore, there is an urgent need to look for a fast-acting and effective antidepressant in the near future. Converging evidence from in vivo brain imaging studies, postmortem investigations, and gene expression studies implicates abnormalities in glutamatergic signaling in the pathophysiology of MDD (Manji et al., 2003; Sanacora et al., 2008; Skolnick et al., 2009). Ketamine, a glutamate N-methyl-d-aspartate (NMDA) receptor antagonist, was associated with rapid antidepressant effects in patients with major depressive disorder in a number of studies and case reports, including treatment-resistant major depression (Berman et al., 2000; Zarate et al., 2006; Mathew et al., 2010; Aan Het Rot et al., 2012). Antidepressant activity by ketamine was observed within hours of a single subanesthetic intravenous infusion, representing a potential paradigm shift in therapeutic approaches for major depressive disorder (Berman et al., 2000). Preclinical studies also showed that ketamine has antidepressant effects in some animal models of depression (Chaturvedi et al. 1999; Maeng et al. 2008a,b; Réus et al. 2015a, b).

The mammalian target of rapamycin (mTOR) is a serine/threonine protein kinase, which modulates cell growth, proliferation, motility, survival, and protein synthesis (Hay and Sonenberg, 2006). Several studies suggest that ketamine and other fast-acting antidepressants, mediated by glutamate and/or neurotrophic receptors, stimulate the mTOR pathway in the prefrontal cortex (PFC) (Li et al., 2010; Palucha-Poniewiera et al., 2014), leading to transient activation of the downstream effectors, 4E-binding protein 1 (4E-BP1) and protein $\mathrm{S} 6$ kinase (p70S6K), which regulate gene expression and protein synthesis (Tang et al., 2015). mTOR is also activated in depressed patients' peripheral blood after acute ketamine administration (Denk et al., 2011; Yang et al., 2013). These studies may indicate an association between marked deficits in synaptic proteins and dysregulation of mTOR signaling in MDD (Karolewicz et al., 2011). It has been reported that neuronal mTOR function is influenced by the activity of growth factors, insulin, cytokines, as well as glutamate activity via NMDA receptors and metabotropic glutamate receptors (mGluR) (Antion et al., 2008; Gong et al., 2006; Hay and Sonenberg, 2006; Hoeffer and Klann, 2010). Activated mTOR phosphorylates p70 ribosomal p70S6K followed by p70S6Kinduced phosphorylation of ribosomal protein $\mathrm{S} 6$ and eukaryotic initiation factor $4 \mathrm{~B}$ (eIF-4B), which promotes the initiation of protein translation (Chandran et al., 2013). mTOR also phosphorylates and inactivates the eukaryotic initiation factor 4E-BP1 reducing its affinity for the eukaryotic initiation factor 4E (eIF4E) leading to release of, eIF4E to facilitate translation initiation (Chandran et al. 2013). Thus, mTOR controls the efficiency of protein translation within cells via its critical downstream targets. Cellular processes, including apoptosis, autophagy, translation, energy metabolism, and inflammation are controlled by the MTOR kinase and the endoplasmic reticulum (ER) stress pathway, also known as the unfolded protein response (UPR) (Appenzeller-Herzog and Hall, 2012). Kato et al. (2012) and Nakajima et al. (2011) pointed out that in some pathological situations cellular toxicity caused by the ER stress are related to chronic activation of mTOR complex 1 (mTORC1). This implies in an apparent paradox in which under specific conditions, mTOR protein, a regulator of cell growth and division, can also signal the cell death (Appenzeller-Herzog and Hall, 2012). Indeed, some studies have already demonstrated that mTORC1 operates both upstream and downstream of ER stress signals, which can either enhance or antagonize the anabolic output of mTORC1 (Polak and Hall, 2009; Hotamisligil, 2010). Upon prolonged ER stress, mTORC1 can contribute to apoptotic signaling by suppressing the survival kinase Akt through feedback inhibition (Polak and Hall, 2009; Hotamisligil, 2010). Likewise, chronic ER stress can also obstruct activation of Akt by mTOR complex 2 (mTORC2). These two signaling networks have traditionally been considered as separate pathways, but the identification of mTORUPR interconnections is a promising new area for research.

There is abundant evidence linking mTOR signaling to synaptic plasticity, memory, neurological disorders and cancer (Gong et al., 2006; Hay and Sonenberg, 2006; Hoeffer and Klann, 2010). However, to date there are no studies that implicate the effects caused by the inhibition of mTOR pathway and treatment with ketamine in the PFC in other brain structures related to depression, such as hippocampus, amygdala and nucleus accumbens; and its relation with proteins of mTOR signaling pathway and UPR. The evaluation and understanding of the intersections and synergisms (or antagonisms) between the outputs of mTOR and UPR is of uttermost importance. Possible routes of crosstalk between these signaling networks are fundamental to cell health. Thus, the aim of this study was to evaluate the effects of the administration of ketamine on the proteins of mTOR signaling pathway, such as mTOR, 4EBP1 and eukaryotic elongation factor 2 kinase (eEF2K), and on the proteins of UPR, such as homologous protein (CHOP), PKR-like ER kinase (PERK) and inositol-requiring enzyme 1 (IRE1)-alpha in the PFC, hippocampus, amygdala and nucleus accumbens, after the inhibiton of mTOR signaling in the PFC.

\section{Material and methods}

\subsection{Animals}

Male Adult (60 days old) Wistar rats, weighing between 250 and $300 \mathrm{~g}$, were housed five to a cage with food and water available ad libitum, and were maintained on a 12-h light/dark cycle (lights on at 7:00 a.m.). In vivo studies were performed in accordance with the National Institutes of Health guidelines and also with the approval of the ethics committee from University of Southern Santa Catarina (UNESC) under protocol 031-2014-01.

\subsection{Experimental design and treatment}

First, all rats ( $\mathrm{n}=20$ total) underwent a surgical procedure to receive a single dose of a pharmacological inhibitor of mTOR (Rapamycin) (from Sigma Aldrich, Brazil) at a dose of $0.2 \mathrm{nmol} / \mathrm{site}$, according with Li et al. (2010), in the PFC, or vehicle (control group) in the PFC. Rapamycin was dissolved in $100 \%$ DMSO and administered in the PFC, in a volume of $3 \mu \mathrm{l}$ per rat. The animals were then divided into four experimental groups: (1) vehicle + saline; (2) rapamycin + saline; (3) vehicle + ketamine $15 \mathrm{mg} / \mathrm{kg}$; and (4) rapamycin + ketamine $15 \mathrm{mg} / \mathrm{kg}$. The intraperitoneal administration of ketamine (from Fort Dodge, Brazil) was performed at $30 \mathrm{~min}$ after the intracerebroventricular (ICV) infusion of rapamycin inhibitor (Li et al., 2010).

\subsection{Surgical procedure}

The animals were anesthetized with chloral hidrate (from Vetec, Brazil) $40 \mathrm{mg} / \mathrm{kg}$ and xylazine (from Bayer, Brazil) $30 \mathrm{mg} / \mathrm{kg}$ intraperitoneally. Using a stereotaxic surgical procedure, the skin and scalp of the rat in the skull region were removed. $1 \mathrm{~mm}$ of length cannula was placed through the brain tissue at the following coordinates: $4.2 \mathrm{~mm}$ behind the bregma, $3.0 \mathrm{~mm}$ to the right of the bregma, with the cannula being inserted $3.4 \mathrm{~mm}$ deep into the PFC (Paxinos and Watson, 1986). The fixation of the cannula tube was made using acrylic cement. The PFC ICV infusion of rapamycin $(3 \mu \mathrm{l})$ or vehicle occurred $72 \mathrm{~h}$ after surgery. 


\subsection{Brain samples and biochemical analysis}

The animals were killed by decapitation, the skulls were removed, then the whole brain was removed and placed in a petri plate that was on ice and then the PFC, hippocampus, nucleus accumbens, and amygdala were quickly isolated by hand dissection using a magnifying glass, a spatula, and a thin brush by a qualified researcher. In addition, the dissection was based on the histological distinctions described by Paxinos and Watson (1986). After the removal of the structures, they were placed in Eppendorf tube and stored in a freezer at $-70{ }^{\circ} \mathrm{C}$ for posterior biochemical analysis. The brain tissues were used for Western Blotting analysis. For biochemical analysis were used a total $n=5$ per group to (one hemispheres for each).

\subsection{Western blotting analysis}

To perform immunoblotting, tissue samples taken from the PFC, hippocampus, amygdala, and nucleus accumbens $(n=5$ per group (20 animals) were homogenized in Laemmli buffer $(62.5 \mathrm{mM}$ TrisHCl, pH 6.8, 1\% (w/v) sodium dodecyl sulfate (SDS), 10\% (v/v) glycerol) and equal amounts of protein $(30 \mu \mathrm{g} / \mathrm{well})$ were electrophoresed by polyacrylamide gel electrophoresis-sodium dodecyl sulfate (SDS-PAGE) and electro transferred to nitrocellulose membranes. The efficiency of the electro transfer was then verified by Ponceau $\mathrm{S}$ staining, and the membrane was then blocked in TrisTween buffer saline (TTBS: $100 \mathrm{mMTriseHCl}$, pH 7.5, containing $0.9 \%$ $\mathrm{NaCl}$ and $0.1 \%$ Tween 20 ) with $5 \%$ albumin. The membranes were incubated overnight at $4{ }^{\circ} \mathrm{C}$ with rabbit polyclonal anti-p4EBP1 $\left(\mathrm{pThr}{ }^{45}\right.$ ) Sigma (SAB4300179) (antibody molecular weight: $18 \mathrm{kDa}$ ), anti-CHOP $\left(\mathrm{pSer}^{30}\right.$ ) from Sigma (SAB4504148) (antibody molecular weight: $19 \mathrm{kDa}$ ), anti-eEF2K from Sigma (SAB450381) (antibody molecular weight: $82 \mathrm{kDa}$ ), anti-mTOR from Sigma (T2949) (antibody molecular weight: $289 \mathrm{kDa}$ ), anti-PERK (C-terminal) from Sigma (P0074) (antibody molecular weight: $150 \mathrm{kDa}$ ), anti-IRE1-alpha (14C10) from Cell Signaling (\#3294) (antibody molecular weight: $130 \mathrm{kDa})(1: 1000)$. Secondary anti-rabbit IgG were incubated with the membrane for $2 \mathrm{~h}$ (1:1000). The membrane was then washed again with TTBS and immunoreactivity was detected by chemiluminescence using ECL. Densitometry analysis of the films was performed using the Image Jv.1.34 image analysis software. All results were expressed as a relative ratio between p4EBP1, CHOP, eEF2K, mTOR, PERK and IRE1-alpha and immunocontent protein $\beta$-actin.

\subsection{Statistical analysis}

All data are presented as mean \pm S.E.M. Differences among experimental groups in the assessment western blotting were determined by one-way ANOVA, followed by Tukey post-hoc test when ANOVA was significant; $\mathrm{p}$ values $<0.05$ were considered to be statistical significant.

\section{Results}

3.1. Effects of ketamine after the inhibition of mTOR pathway in the PFC with rapamycin on $m T O R, p 4 E B P 1$ and eEF2K levels in brain structures

Fig. 1 illustrates the effect of ketamine after the inhibition of mTOR in the PFC on proteins related to the mTOR signaling pathway in the PFC, hippocampus, amygdala and nucleus accumbens. mTOR levels were decreased in the PFC in the rapamycin group treated with saline when compared to the vehicle group treated with saline and in the rapamycin group treated with ketamine when compared to vehicle group treated to saline and to vehicle group treated with ketamine $\left(\mathrm{F}_{(3-12)}=11.335 ; p=0.003\right.$; Fig. 1A), showing that rapamycin was able to block the mTOR levels and abolish ketamine effects. There was no statistical difference on mTOR levels in the hippocampus $\left(\mathrm{F}_{(3-12)}=1.213 ; p=0,365\right.$; Fig. 1A), in the amygdala $\left(\mathrm{F}_{(3-15)}=2.204 ; p=0.140\right.$; Fig. $\left.1 \mathrm{~A}\right)$ and in the nucleus accumbens $\left(\mathrm{F}_{(3-12)}=0.494 ; p=0.694\right.$; Fig. $\left.1 \mathrm{~A}\right)$. Fig. $1 \mathrm{~B}$ demonstrates that p4EBP1 levels were decreased in PFC in the rapamycin group treated with ketamine when compared to vehicle group treated with saline, vehicle group treated with ketamine and to rapamycin group treated with saline $\left(\mathrm{F}_{(3-15)}=4.596 ; p=0.013\right.$; Fig. 1B). In hippocampus there was a decrease in the rapamycin group treated with ketamine when compared to vehicle group treated with ketamine $\left(\mathrm{F}_{(3-15)}=2.264 ; p<0.05\right.$; Fig. 1B). There was no statistical difference on p4EBP1 levels in amygdala ( $F$ (3$15)=1.091 ; p=0.390 ;$ Fig. $1 \mathrm{~B})$ and in the nucleus accumbens $\left(\mathrm{F}_{(3-}\right.$ $15)=1.617 ; p=0.237 ;$ Fig. 1B). Fig. $1 \mathrm{C}$ shows that eEF2K levels were increased in PFC in the vehicle group treated with ketamine when compared to vehicle group treated with saline, and it were decreased in the rapamycin group treated with ketamine when compared to vehicle group treated with ketamine $\left(\mathrm{F}_{(3-14)}=7.260\right.$; $p=0.006$; Fig. 1C). There was no statistical difference on eEF2K levels in the amygdala $\left(\mathrm{F}_{(3-15)}=2.554 ; p=0.104\right.$; Fig. 1C), hippocampus $\left(\mathrm{F}_{(3-15)}=1.038 ; p=0.411 ; \mathrm{Fig} .1 \mathrm{C}\right)$ and nucleus accumbens $\left(\mathrm{F}_{(3-14)}=0.253 ; p=0.857\right.$; Fig. $\left.1 \mathrm{C}\right)$.

\subsection{Effects of ketamine after the inhibition of mTOR pathway in the PFC with rapamycin on UPR signaling pathway, such as CHOP, IRE1- alpha and PERK levels in brain structures}

Fig. 2 illustrates the effect of ketamine, after the inhibition of mTOR in the PFC on proteins related to the UPR signaling pathway in the PFC, hippocampus, amygdala and nucleus accumbens. There were no statistical differences on CHOP levels in the PFC ( $\mathrm{F}$ (3$15)=1.186 ; p=0.356 ;$ Fig. $2 \mathrm{~A})$, amygdala $\left(\mathrm{F}_{(3-15)}=0.538 ; p=0.664\right.$; Fig. 2A), hippocampus $\left(\mathrm{F}_{(3-15)}=1.997 ; p=0.168\right.$; Fig. $\left.2 \mathrm{~A}\right)$ and nucleus accumbens $\left(\mathrm{F}_{(3-15)}=0.584 ; p=0.636\right.$; Fig. $\left.2 \mathrm{~A}\right)$ after the inhibition of mTOR pathway in PFC. IRE1-alpha levels were decreased in the PFC in the rapamycin group treated with ketamine when compared to rapamycin group treated with saline ( $\mathrm{F}$ (3$15)=2.470 ; p<0.05$; Fig. 2B). Any statistical differences were observed on IRE1-alpha levels in the hippocampus, $\left(\mathrm{F}_{(3-15)}=0.857\right.$; $p=0.494$; Fig. 2B), amygdala $\left(\mathrm{F}_{(3-15)}=0.857 ; p=0.145\right.$ Fig. $\left.2 \mathrm{~B}\right)$ and in the nucleus accumbens $\left(\mathrm{F}_{(3-15)}=1.189 ; p=0.355\right.$ Fig. $\left.2 \mathrm{~B}\right)$.

Fig. 2C demonstrates that PERK levels were decreased in PFC in the rapamycin group treated with ketamine when compared to rapamycin group treated with saline $\left(\mathrm{F}_{(3-15)}=3.803 ; p=0.046\right.$; Fig. 2C). There was no difference on PERK levels in the amygdala ( $\mathrm{F}$ $(3-15)=3.363 ; p=0.063$; Fig. $2 \mathrm{C})$, hippocampus $\left(\mathrm{F}_{(3-15)}=2.449\right.$; $p=0.114$; Fig. $2 \mathrm{C})$ and in the nucleus accumbens $\left(\mathrm{F}_{(3-15)}=2.900\right.$; $p=0.087$; Fig. 2C).

\section{Discussion}

mTOR is a protein kinase involved in cell proliferation, mortality, survival, and protein synthesis (Hay and Sonenberg, 2006). Changes in this signaling cascade have been hypothesized to be a common pathophysiological feature of neuropsychiatric disorders (Hoeffer and Klann, 2010). In fact, a postmortem study showed considerable deficits in mTOR signaling in the PFC of subjects diagnosed with MDD (Jernigan et al., 2011). Rapid activation of the mTOR signaling pathway resulting in rapid elevation of synapseassociated proteins represents a mechanism for the rapid antidepressant effect of the NMDAR antagonist ketamine (Li et al., 2010). The rapid activation of the mTOR signaling pathway is mediated by 

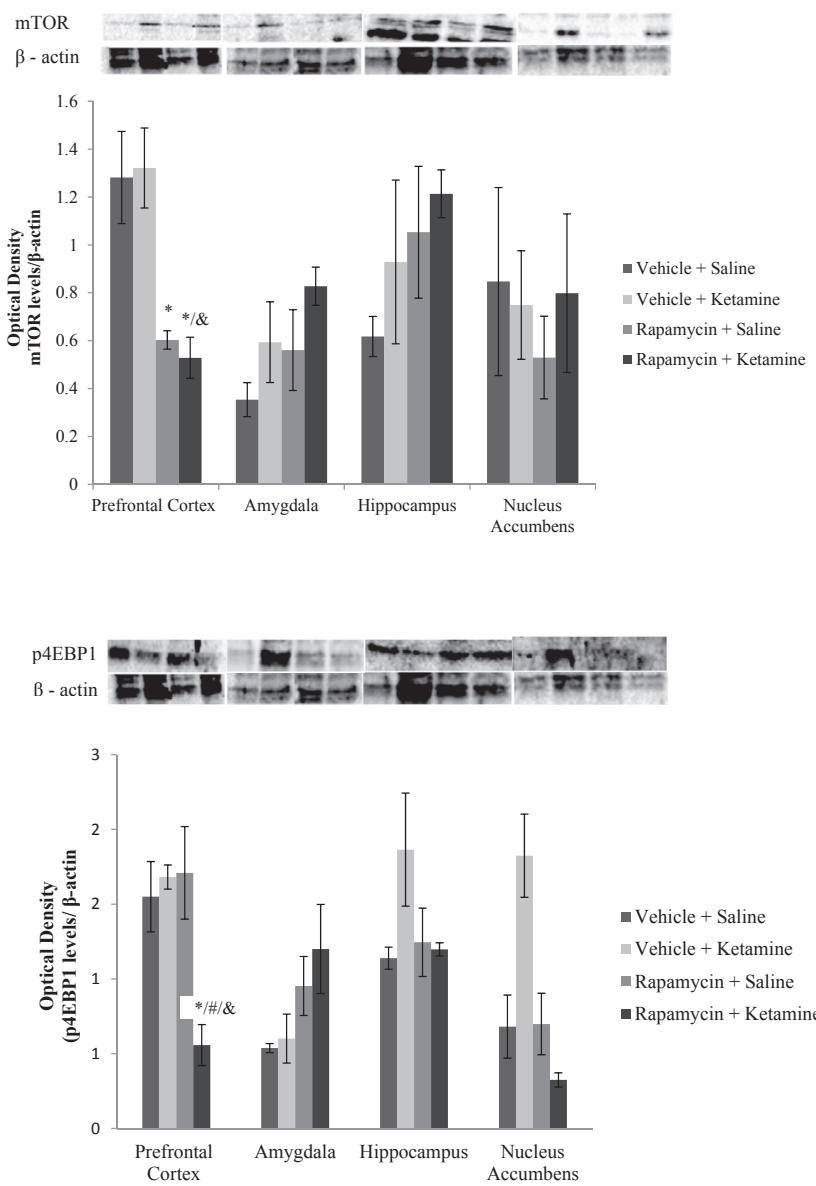

C
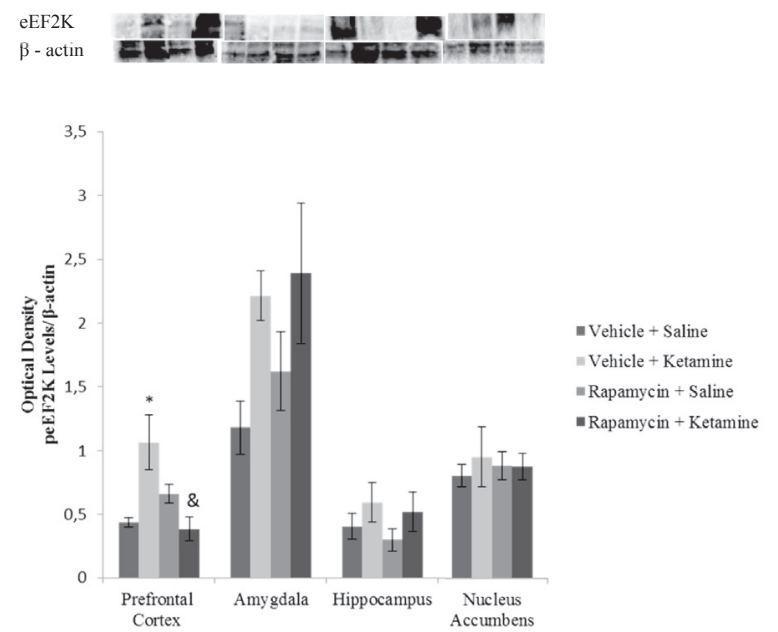

Fig. 1. The effects of ketamine administration after the infusion of inhibitor rapamycin in the PFC on mTOR (A), p4EBP1 (B), eEF2K (C) levels in the prefrontal cortex, hippocampus, amygdala and nucleus accumbens. Representative images of each protein and mTOR (A), p4EBP1 (B), eEF2K (C) and $\beta$-actin, respectively are shown in the upper panels. Bars represent mean standard deviation ( $\mathrm{n}=5$ per group). ${ }^{*} p<0.05$ vs. vehicle + saline; $\# p<0.05$ vs. rapamycin + saline; $\& p<0.05$ vs. vehicle + ketamine according to ANOVA followed by Tukey post hoc test.
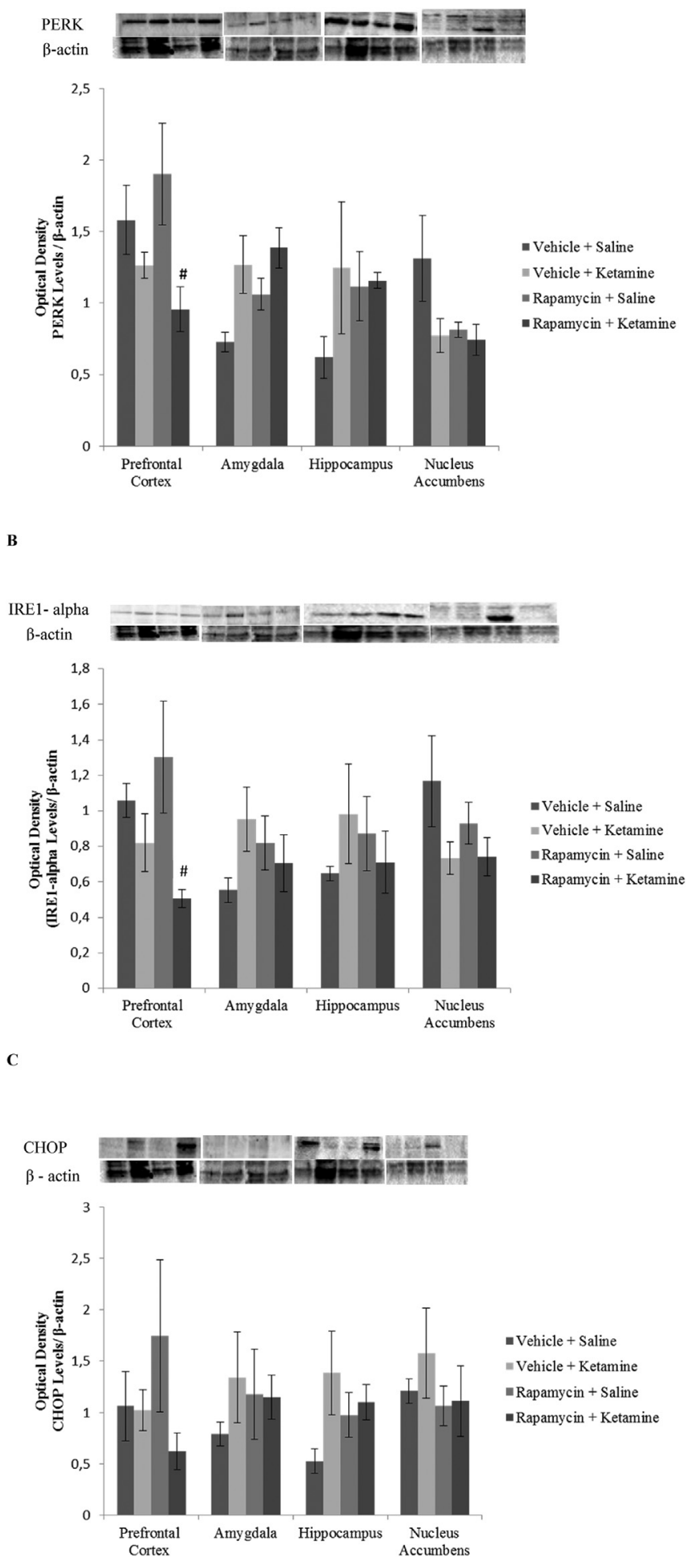

Fig. 2. The effects of ketamine administration after the infusion of inhibitor rapamycin in the PFC on PERK (A), IRE1-alpha (B), CHOP (C) levels in the prefrontal cortex, hippocampus, amygdala and nucleus accumbens. Representative images of each protein and PERK (A), IRE1-alpha (B), CHOP (C) and $\beta$-actin, respectively are shown in the upper panels. Bars represent mean standard deviation ( $\mathrm{n}=5$ per group). $\# p<0.05$ vs. rapamycin + saline; according to ANOVA followed by Tukey post hoc test. 
the stimulation of the $\alpha$-amino-3-hydroxy-5-methyl-4-isoxazole propionic acid receptor (AMPAR) (Maeng et al. 2008a,b; Li et al., 2010). Moreover, rapamycin, a specific inhibitor of mTOR signaling, which inhibits mTORC1 but not mTORC2, completely blocked ketamine-induced synaptogenesis and antidepressive effects in rats PFC (Li et al. 2010). Our results also showed that rapamycin was able to block the mTOR protein in the PFC and still, rapamycin abolished the ketamine antidepressant effects. Studies using animal models of depression suggest a role of the PFC in the pathophysiology of depression and antidepressants responses (Chang et al., 2015). In fact, some studies showed that MDD involve alterations to the behavioral control system supported by the PFC and its connectivity with other brain systems (Phillips et al., 2003; Godsil et al., 2013). In addition, Genzel et al. (2015) and Yu et al. (2013) demonstrated that patients with MDD display an alteration on functional connectivity in the PFC-hippocampus and the PFC-amygdala pathways. mTOR regulates protein synthesis through the phosphorylation and inactivation of the repressor of mRNA translation, 4E-BP1 (Hay and Sonenberg, 2006). Phosphorylation of 4E-BP1 controls cap-dependent translation of mRNAs with extensive secondary structure (Sonenberg, 1996). This downstream effector of mTOR whose phosphorylation is inhibited by rapamycin in vivo, can be phosphorylated by recombinant mTOR in vitro (Brunn et al., 1997; Burnett et al., 1998). In fact, our results showed that the 4E-BP1 levels were decrease in the PFC and in the nucleus accumbens in rapamycin group treated with ketamine, demonstrating that rapamycin was able to block ketamine effects. Li et al. (2010) showed that inhibition of either ERK (U0126) or Akt (via inhibition of the upstream Akt activator PI3 kinase by LY294002) also blocked ketamine-induction of phosphorylated 4EBP1 in the PFC. However, this is the first study to show these effects in 4E-BP1 levels in the nucleus accumbens after the inhibition of mTOR signaling in the PFC. Some studies have shown that acute and chronic exposure to drugs of abuse is associated with increased mTORC1 activity in reward-relevant brain regions, particularly nucleus accumbens (James et al., 2014; Neasta et al., 2010; Wu et al., 2011). Consistent with the role of mTORC1 in synaptic protein translation, rapamycin treatment also significantly reduced GluA1 AMPAR subunit and S6K levels in the nucleus accumbens (James et al., 2016). In addition, other studies also showed that acute intra-accumbal rapamycin infusions are effective at reducing psychostimulant reinstatement (Wang et al., 2010) and sensitization behavior (Narita et al, 2005; James et al. 2016). One of the main downstream targets of mTOR is p70 ribosomal protein S6K, which promotes the initiation of protein translation and regulates translation elongation via the activation of the eEF2 kinase (Laplante and Sabatini, 2009; Hoeffer and Klann, 2010). eEF2K is a Ca2+l calmodulin-dependent serine/threonine kinase important for the regulation of elongation of protein translation (Monteggia et al., 2013). Elongation is a highly energy-consuming process, and eEF2K activity is tightly regulated by several signaling pathways (Liu and Proud, 2016). eEF2K is expressed in neurons, and recent evidence suggests that it may play a role in processes such as learning and memory and in depression (Liu and Proud, 2016). In fact, Park et al. (2008) showed that eEF2K plays an important role in the synthesis of $\operatorname{Arc} / \operatorname{Arg} 3.1$, a protein involved in neurotransmitter receptor trafficking and in long-term depression, a process that reflects changes in synaptic strength. In this way, our results showed that the infusion of rapamycin abolished the ketamine effects in the PFC and when ketamine was administrated alone was able to increase the eEF2K levels. Some studies have suggested that ketamine exerts its effects on the expression of brain-derived growth factor (BDNF), an important neuroregulatory protein, via the inhibition of eEF2K signaling, which normally negatively regulates BDNF expression (Nosyreva and Kavalali, 2010; Autry et al.,
2011). In fact, previous study showed that chronic treatment with ketamine was able to reverse the decrease in the BDNF protein levels in the hippocampus and nucleus accumbens of rats submitted to the maternal deprivation (Réus et al., 2015c). However, Heise et al. (2014) demonstrated that ketamine enhances BDNF expression and exerts antidepressant effects in wild-type mice but not in animals with eEF2K knock out. This is the first study to show the effects of ketamine in eEF2K levels in brain structures after the inhibition on mTOR, by rapamcyin, in the PFC. However, our results did not show statistical relevance in the hippocampus, amygdala and nucleus accumbens, only in the PFC. In addition, our study suggest that the eEF2K effects on phosphorylation and regulation of elongation step of protein translation could be also a major molecular mechanism of the rapid antidepressant effect of ketamine. ER, a major site for protein synthesis, folding, and calcium signaling, is highly sensitive to alterations in calcium homeostasis and perturbations (Rao et al., 2004a). ER stress, a condition that impairs the function of the ER, can lead to an accumulation of unfolded proteins in the ER lumen (Rao et al., 2004b). Three major UPR branches, PERK, IRE1-alpha, and activation of transcription factor 6 (ATF6) have been described to promote cell survival by preventing and/or removing misfolded proteins (Chen et al., 2014). The UPR transducers are activated by phosphorylating PERK and IRE1-alpha or by translocating ATF6 to the Golgi when the ER is stressed (Chen et al., 2014). Subsequently, a cascade of reactions follows, activating numerous ER stress molecules that serve as measurable mechanism-based ER stress markers, such as phosphorylation of eukaryotic initiation factor 2 (eIF2 $\alpha$ ) and activation of CHOP (Dara et al., 2011; Xu et al., 2005). Excessive and prolonged ER stress can trigger cell death (McCullough et al., 2001) and ER stress is associated with depression (Gold et al., 2013). In fact, Nevell et al. (2014) found persistent activation of the ER stress response in peripheral tissues of MDD patients. In addition, some studies have reported a relationship bethween ER stress and mTOR-signaling pathway (Polak and Hall, 2009; Hotamisligil, 2010). Our results showed that there was a decrease on PERK and IRE1-alpha levels in the PFC in rapamycin group treated with ketamine, suggesting that rapamycin was able to block the ketamine effects on these parameters. In addition, our results did not show effects on CHOP levels in the brain. Chen et al. (2014) reported that protein expression of major ER stress markers, such as PERK, pPERK and CHOP was induced by exposure to antidepressant sertraline, a selective serotonin reuptake inhibitor (SSRI). However, other study demonstrated that fluvoxamine, a SSRI, did not alter the PERK levels (Omi et al., 2014). The interplay between ER stress and mTORC1 is complex, since the UPR activation can occur upstream or downstream of mTORC1. Persistent activation of mTORC1 initiates protein synthesis and UPR activation, while in the later phase induces ER stress (Wang et al., 2016). However, our study showed that when ketamine was blocked by rapamycin, it was able to decrease the ER stress markers, suggesting that ketamine antidepressant effects on ER stress pathway could be also mediated by mTOR signaling pathway.

In conclusion, this work is, to our knowledge, the first study to show the effects of ketamine after the inhibition of mTOR by rapamycin on mTOR signaling pathway and the relationship of this inhibition and ketamine effects on ER stress signaling in the PFC. Rapamycin was able to abolish ketamine antidepressant effects in both mTOR and ER signaling pathway in some brain areas, suggesting that mTOR signaling inhibition by rapamycin could be involved, at least in part, with the mechanism of action of ketamine, and the ketamine antidepressant on ER stress pathway could be also mediated by mTOR signaling pathway. However, further studies are necessary to better explain how these intrinsic effects occur. 


\section{Contributors}

GZR, HMA and JQ performed the research; ZMI, HMA, MABS, $\mathrm{DM}, \mathrm{JPD}, \mathrm{ABM}$ and JBIS worked on surgical structures procedures, the pharmacological treatment, and in the removal of brain structures; MM, MA, BS and FDP worked on the western blotting analysis. HMA and GZR analyzed the data and wrote the paper. All authors approved the final version of the manuscript.

\section{Conflict of interest}

The authors have no potential conflict of interest.

\section{Role of funding source}

None.

\section{Acknowledgements}

The Translational Psychiatry Program (USA) is funded by the Department of Psychiatry and Behavioral Sciences, McGovern Medical School, The University of Texas Health Science Center at Houston (UTHealth). Laboratory of Neurosciences (Brazil) is one of the centers of the National Institute for Molecular Medicine (INCT$\mathrm{MM}$ ) and one of the members of the Center of Excellence in Applied Neurosciences of Santa Catarina (NENASC). Its research is supported by grants from CNPq (JQ and FDP), FAPESC (JQ and FDP); Instituto Cérebro e Mente (JQ) and UNESC (JQ and FDP). JQ and FDP are $1 \mathrm{~A}$ CNPq Research Fellow.

\section{References}

Aan Het Rot, M., Zarate Jr., C.A., Charney, D.S., Mathew, S.J., 2012. Ketamine for depression: where do we go from here? Biol. Psychiatry 72, 537-547.

Antion, M.D., Hou, L., Wong, H., Hoeffer, C.A., Klann, E., 2008. mGluR-dependent long-term depression is associated with increased phosphorylation of S6 and synthesis of elongation factor $1 \mathrm{~A}$ but remains expressed in S6K-deficient mice. Mol. Cell. Biol. 28, 2996-3007.

Appenzeller-Herzog, C., Hall, M.N., 2012. Bidirectional crosstalk between endoplasmic reticulum stress and mTOR signaling. Trends Cell. Biol. 22, 274-282.

Autry, A.E., Adachi, M., Nosyreva, E., Na, E.S., Los, M.F., Cheng, P.F., et al., 2011. NMDA receptor blockade at rest triggers rapid behavioural antidepressant responses. Nature 475, 91-95.

Berman, R.M., Cappiello, A., Anand, A., Oren, D.A., Heninger, G.R., Charney, D.S., Krystal, J.H., 2000. Antidepressant effects of ketamine in depressed patients. Biol. Psychiatry 47, 351-354.

Brunn, G.J., Hudson, C.C., Sekulic, A., Williams, J.M., Hosoi, H., Houghton, P.J., Lawrence Jr., J.C., Abraham, R.T., 1997. Phosphorylation of the translational repressor PHAS-I by the mammalian target of rapamycin. Science 277, 99-101.

Burnett, P.E., Barrow, R.K., Cohen, N.A., Snyder, S.H., Sabatini, D.M., 1998. RAFT1 phosphorylation of the translational regulators p70 S6 kinase and 4E-BP1. Proc. Natl. Acad. 95, 1432-1437.

Chandran, A., Iyo, A.H., Jernigan, C.S., Legutko, B., Austin, M.C., Karolewicz, B., 2013. Reduced phosphorylation of the mTOR signaling pathway components in the amygdala of rats exposed tochronic stress. Prog. Neuropsychopharmacol. Biol. Psychiatry 40, 240-245.

Chang, C.H., Chen, M.C., Lu, J., 2015. Effect of antidepressant drugs on the vmPFClimbic circuitry. Neuropharmacology 92, 116-124.

Chaturvedi, H.K., Chandra, D., Bapna, J.S., 1999. Interaction between N-methyl-Daspartate receptor antagonists and imipramine in shock-induced depression. Indian J. Exp. Biol. 37, 952-958.

Chen, S., Xuan, J., Couch, L., Iyer, A., Wu, Y., Li, Q.Z., Guo, L., 2014. Sertraline induces endoplasmic reticulum stress in hepatic cells. Toxicology 322, 78-88.

Dara, L., Ji, C., Kaplowitz, N., 2011. The contribution of endoplasmic reticulum stressto liver diseases. Hepatology 53, 1752-1763.

Denk, M.C., Rewerts, C., Holsboer, F., Erhardt-Lehmann, A., Turck, C.W., 2011. Monitoring ketamine treatment response in a depressed patient via peripheral mammalian target of rapamycin activation. Am. J. Psychiatry 168, 751-752.

Genzel, L., Dresler, M., Cornu, M., et al., 2015. Medial prefrontal-hippocampal connectivity and motor memory consolidation in depression and schizophrenia. Biol. Psychiatry 77, 177-186.

Ghasemi, M., Phillips, C., Trillo, L., De Miguel, Z., Das, D., Salehi, A., 2014. The role of NMDA receptors in the pathophysiology and treatment of mood disorders. Neurosci. Biobehav. Rev. 47, 336-358.

Giacobbe, P., Mayberg, H.S., Lozano, A.M., 2009. Treatment resistant depression as a failure of brain homeostatic mechanisms: implications for deep brain stimulation. Exp. Neurol. 219, 44-52.

Godsil, B.P., Kiss, J.P., Spedding, M., Jay, T.M., 2013. The hippocampal-prefrontal pathway: the weak link in psychiatric disorders? Eur. Neuropsychopharmacol. 23, 1165-1181.

Gold, P.W., Licinio, J., Pavlatou, M.G., 2013. Pathological parainflammation and endoplasmic reticulum stress in depression: potential translational targets through the CNS insulin, klotho and PPAR-gamma systems. Mol. Psychiatry 18 154-165.

Gong, R., Park, C.S., Abbassi, N.R., Tang, S.J., 2006. Roles of glutamate receptors and the mammalian target of rapamycin (mTOR) signaling pathway in activitydependent dendritic protein synthesis in hippocampal neurons. J. Biol. Chem. 281, 18802-18815.

Hay, N., Sonenberg, N., 2006. Upstream and downstream of mTOR. Genes Dev. 18, $1926-1945$.

Heise, C., Gardoni, F., Culotta, L., Di, L.M., Verpelli, C., Sala, C., 2014. Elongation factor-2 phosphorylation in dendrites and the regulation of dendritic mRNA translation in neurons. Front. Cell. Neurosci. 8, 35.

Hoeffer, C.A., Klann, E., 2010. mTOR signaling: at the crossroads of plasticity, memory and disease. Trends Neurosci. 33, 67-75.

Hotamisligil, G.S., 2010. Endoplasmic reticulum stress and the inflammatory basis of metabolic disease. Cell 140, 900-917.

James, M.H., Quinn, R.K., Ong, L.K., Levi, E.M., Charnley, J.L., Smith, D.W Dickson, P.W., Dayas, C.V., 2014. mTORC1 inhibition in the nucleus accumbens 'protects' against the expression of drugs eeking and'relapse' and is associated with reductions in GluA1 AMPAR and CAMKII alpha levels. Neuropsychopharmacol 39, 1694-1702.

James, M.H., Quinn, R.K., Ong, L.K., Levi, E.M., Smith, D.W., Dickson, P.W., Dayas, C.V., 2016. Rapamycin reduces motivated responding for cocaine and alters GluA1 expression in the ventral but not dorsal striatum. Eur. J. Pharmacol. 784, 147-154.

Jernigan, C.S., Goswami, D.B., Austin, M.C., Iyo, A.H., Chandran, A., Stockmeier, C.A., Karolewicz, B., 2011. The mTOR signaling pathway in the prefrontal cortex is compromised in major depressive disorder. Prog. Neuropsychopharmacol. Biol. Psychiatry 35, 1774-1779.

Karolewicz, B., Cetin, M., Aricioglu, F., 2011. Beyond the glutamate N-methyl Daspartate receptor in major depressive disorder: the mTOR signaling pathway Bull. Clin. Psychopharmacol. 21, 1-6.

Kato, H., Nakajima, S., Saito, Y., Takahashi, S., Katoh, R., Kitamura, M., 2012. mTORC1 serves ER stress-triggered apoptosis via selective activation of the IRE1-JNK pathway. Cell. Death Differ. 19, 310-320.

Laplante, M., Sabatini, D.M., 2009. mTOR signaling at a glance. J. Cell. Sci. 122, 3589-3594.

Li, N., Lee, B., Liu, R.J., Banasr, M., Dwyer, J.M., Iwata, M., Li, X.Y., 2010. Aghajanian G, Duman RS. mTOR-dependent synapse formation underlies the rapid antidepressant effects of NMDA antagonists. Science 329, 959-964.

Liu, R., Proud, C.G., 2016. Eukaryotic elongation factor 2 kinase as a drug target in cancer, and in cardiovascular and neurodegenerative diseases. Acta Pharmacol Sin. 37, 285-294.

Machado-Vieira, R., Salvadore, G., Diazgranados, N., Zarate Jr., C.A., 2009. Ketamine and the next generation of antidepressants with a rapid onset of action. Pharmacol. Ther. 123, 143-150.

Maeng, S., Zarate Jr., C.A., Du, J., et al., 2008a. Cellular mechanisms underlying the antidepressant effects of ketamine: role of alpha-amino-3-hydroxy-5methylisoxazole-4-propionic acid receptors. Biol. Psychiatry 63, 349-352.

Maeng, S., Zarate Jr., C.A., Du, J., Schloesser, R.J., McCammon, J., Chen, G., et al., 2008b. Cellular mechanisms under lying the antidepressant effects of ketamine: role of alpha-amino-3-hydroxy-5-methylisoxazole-4-propionic acid receptors. Biol. Psychiatry 63, 349-352.

Manji, H.K., Quiroz, J.A., Sporn, J., Payne, J.L., Denicoff, K.A., Gray, N., Zarate Jr., C.A., Charney, D.S., 2003. Enhancing neuronal plasticity and cellular resilience to develop novel, improved therapeutics for difficult-to-treat depression. Biol. Psychiatry 53, 707-742.

Mathew, S.J., Murrough, J.W., aan het Rot, M., Collins, K.A., Reich, D.L., Charney, D.S. 2010. Riluzole for relapse prevention following intravenous ketamine in treatment-resistant depression: a pilot randomized, placebo-controlled continuation trial. Int. J. Neuropsychopharmacol. 13, 71-82.

McCullough, K.D., Martindale, J.L., Klotz, L.O., Aw, T.Y., Holbrook, N.J., 2001. Gadd153 sensitizes cells to endoplasmic reticulum stress by downregulating $\mathrm{Bcl} 2$ and perturbing the cellular redox state. Mol. Cell. Biol. 21, 1249-1259.

Monteggia, L.M., Gideons, E., Kavalali, E.T., 2013. The role of eukaryotic elongation factor 2 kinase in rapid antidepressant action of ketamine. Biol. Psychiatry 73 $1199-1203$.

Nakajima, S., Hiramatsu, N., Hayakawa, K., Saito, Y., Kato, H., Huang, T., Yao, J., Paton, A.W., Paton, J.C., Kitamura, M., 2011. Selective abrogation of BiP/GRP78 blunts activation of NF- $\mathrm{B}$ B through the ATF6 branch of the UPR: involvement of C/EBP $\beta$ and mTOR-dependent dephosphorylation of Akt. Mol. Cell. Biol. 31, $1710-1718$

Narita, M., Akai, H., Kita, T., Nagumo, Y., Narita, M., Sunagawa, N., Hara, C., Hasebe, K., Nagase, H., Suzuki, T., 2005. Involvement of mitogen-stimulated p70-S6 kinase in the development of sensitization to the methamphetamineinduced rewarding effect in rats. Neuroscience 132, 553-560.

Naughton, M., Clarke, G., O'Leary, O.F., Cryan, J.F., Dinan, T.G., 2014. A review of ketamine in affective disorders: current evidence of clinical efficacy, limitations of use and pre-clinical evidence on proposed mechanisms of action. J. Affect. Disord. 156, 24-35. 
Neasta, J., BenHamida, S., Yowell, Q., Carnicella, S., Ron, D., 2010. Role for mammalian target of rapamycin complex1signaling in neuroadaptation sunderlying alcohol-related disorders. Proc. Natl. Acad. Sci. U. S. A. 107, 20093-20098.

Nevell, L., Zhang, K., Aiello, A.E., Koenen, K., Galea, S., Soliven, R., et al., 2014. Elevated system icexpression of ER stress related genes is associated with stress-related mental disorders in the Detroit Neighborhood Health Study. Psychoneuroendocrinology 43, 62-70.

Nosyreva, E., Kavalali, E.T., 2010. Activity-dependent augmentation of spontaneous neurotransmission during endoplasmic reticulum stress. J. Neurosci. 30, 7358-7368.

Omi, T., Tanimukai, H., Kanayama, D., Sakagami, Y., Tagami, S., Okochi, M., Morihara, T., Sato, M., Yanagida, K., Kitasyoji, A., Hara, H., Imaizumi, K. Maurice, T., Chevallier, N., Marchal, S., Takeda, M., Kudo, T., 2014. Fluvoxamine alleviates ER stress via induction of Sigma-1 receptor. Cell. Death Dis. 5, e1332.

Palucha-Poniewiera, A., Szewczyk, B., Pilc, A., 2014. Activation of the mTOR signaling pathway in the antidepressant-like activity of the mGlu5 antagonist MTEP and the mGlu7 agonist AMN082 in the FST in rats. Neuropharmacology 82, 59-68.

Park, S., Park, J.M., Kim, S., Kim, J.A., Shepherd, J.D., Smith-Hicks, C.L., et al., 2008 Elongation factor 2 and fragile $\mathrm{X}$ mental retardation protein control the dy namic translation of Arc/Arg3.1 essential for mGluR-LTD. Neuron 59, 70-83.

Paxinos, G., Watson, C., 1986. The Rat Brain: Stereotaxic Coordinates, second ed Academic Press, Australia.

Phillips, M.L., Drevets, W.C., Rauch, S.L., Lane, R., 2003. Neurobiology of emotion perception I: the neural basis of normal emotion perception. Biol. Psychiatry 54 504-514.

Polak, P., Hall, M.N., 2009. mTOR and the control of whole body metabolism. Curr. Opin. Cell. Biol. 21, 209-218.

Rao, R.V., Ellerby, H.M., Bredesen, D.E., 2004a. Coupling endoplasmic reticulum stress to the cell death program. Cell. Death Differ. 11, 372-380.

Rao, R.V., Poksay, K.S., Castro-Obregon, S., Schilling, B., Row, R.H., del Rio, G. Gibson, B.W., et al., 2004b. Molecular components of a cell death pathway activated by endoplasmic reticulum stress. J. Biol. Chem. 279, 177-187.

Réus, G.Z., Nacif, M.P., Abelaira, H.M., Tomaz, D.B., dos Santos, M.A., Carlessi, A.S., da Luz, J.R., Gonçalves, R.C., Vuolo, F., Dal-Pizzol, F., Carvalho, A.F., Quevedo, J., 2015a. Ketamine ameliorates depressive-like behaviors and immune alterations in adult rats following maternal deprivation. Neurosci. Lett. 584, 83-87.

Réus, G.Z., Carlessi, A.S., Titus, S.E., Abelaira, H.M., Ignácio, Z.M., da Luz, J.R. Matias, B.I., Bruchchen, L., Florentino, D., Vieira, A., Petronilho, F., Quevedo, J. 2015b. A single dose of S-ketamine induces long-term antidepressant effects and decreases oxidative stress in adulthood rats following maternal deprivation. Dev. Neurobiol. 75, 1268-1281.

Réus, G.Z., Nacif, M.P., Abelaira, H.M., Tomaz, D.B., dos Santos, M.A., Carlessi, A.S., Matias, B.I., da Luz, J.R., Steckert, A.V., Jeremias, G.C., Scaini, G., Morais, M.O., Streck, E.L., Quevedo, J., 2015c. Ketamine treatment partly reverses alterations in brain derived- neurotrophic factor, oxidative stress and energy metabolism parameters induced by an animal model of depression. Curr. Neurovasc. Res. 12, 73-84.

Sanacora, G. Zarate, C.A., Krystal, J.H., Manji, H.K., 2008. Targeting the glutamatergic system to develop novel, improved therapeutics for mood disorders. Nat. Rev. Drug Discov. 7, 426-437.

Skolnick, P., Popik, P., Trullas, R., 2009. Glutamate-based antidepressants: 20 years on. Trends Pharmacol. Sci. 30, 563-569.

Sonenberg, N., 1996. In: Hershey, J.W.B., Mathews, M.B., Sonenberg, N. (Eds.), Translational Control. Cold Spring Harbor Lab. Press, Plainview, NY pp. 245-269.

Tang, J., Xue, W., Xia, B., Ren, L., Tao, W., Chen, C., Zhang, H., Wu, R., Wang, O., Wu, H., Duan, J., Chen, G., 2015. Involvement of normalized NMDA receptor and mTORrelated signaling in rapid antidepressant effects of Yuejuand ketamine on chronically stressed mice. Sci. Rep. 5, 13573.

Wang, J., Yang, X., Zhang, J., 2016. Bridges between mitochondrial oxidative stress, ER stress and mTOR signaling in pancreatic $\beta$ cells. Cell. Signal 28, 1099-1104.

Wang, X., Luo, Y.X., He, Y.Y, Li, F.Q. Shi, H.S., Xue, L.F., Xue, Y.X., Lu, L., 2010. Nucleus accumbens core mammalian target of rapamycin signaling pathway is critical for cue-induced reinstatement of cocaine seeking in rats. J. Neurosci. 30, $12632-12641$

Wu, J., McCallum, S.E., Glick, S.D., Huang, Y., 2011. Inhibition of the mammalian target of rapamycin pathway by rapamycin blocks cocaine-induced locomotor sensitization. Neuroscience 172, 104-109.

Xu, C., Bailly-Maitre, B., Reed, J.C., 2005. Endoplasmic reticulum stress: cell life anddeath decisions. J. Clin. Investig. 115, 2656-2664.

Yang, C., Zhou, Z.Q., Gao, Z.Q., Shi, J.Y., Yang, J.J., 2013. Acute increases in plasma Mammalian target of rapamycin, glycogen synthase kinase-3b, and eukaryotic elongation factor 2 phosphorylation after ketamine treatment in three depressed patients. Biol. Psychiatry 73 e35-6.

Yu, Y., Shen, H., Zeng, L.L., Ma, Q., Hu, D., 2013. Convergent and divergent functional connectivity patterns in schizophrenia and depression. PLoS One 8, 7.

Zarate Jr., C.A., Singh, J.B., Carlson, P.J., Brutsche, N.E., Ameli, R., Luckenbaugh, D.A., Charney, D.S., Manji, H.K., 2006. A randomized trial of an Nmethyl- D-aspartate antagonist in treatment-resistant major depression. Arch. Gen. Psychiatry 63, 856-864. 